\title{
Fabrication of Photocrosslinked Polysilane/diarylfluorene Blended Films with Tunable Refractive Indices
}

\author{
Haruyuki Okamura $^{1 *}$, Masashi Iseki ${ }^{1}$, Kaai Degawa ${ }^{1}$, Akikazu Matsumoto ${ }^{1}$, \\ Keiko Minokami², and Shinsuke Miyauchi
}

\author{
${ }^{1}$ Department of Applied Chemistry, Graduate School of Engineering, \\ Osaka Prefecture University, 1-1 Gakuen-cho, Naka-ku, Sakai, Osaka 599-8531, Japan \\ ${ }^{2}$ Fine Materials Business Division, Osaka Gas Chemicals Co., Ltd., \\ 5-11-61, Torishima, Konohana-ku, Osaka 554-0051, Japan \\ *okamura@chem.osakafu-u.ac.jp
}

\begin{abstract}
We have developed the photocrosslinked films of a diphenyl- or dinaphthylfluorene having epoxy and oxetane moieties and polysilanes blends in the presence of a photoacid generator by irradiation at $405 \mathrm{~nm}$. Photo-induced decomposition of the Si-Si bonds of the polysilanes was successfully suppressed during the visible light irradiation. The cationic photocrosslinking properties of the blends were strongly affected by the post-exposure-bake conditions and irradiation dose. Polysilane moieties were incorporated into the film by the termination reaction of the polymerization with the terminal $\mathrm{OH}$ groups. We have successfully fabricated films with high refractive indices $\left(n_{\mathrm{d}}: 1.70\right)$ and the refractive index values were tunable by irradiation at $254 \mathrm{~nm}$ due to the decomposition of the Si-Si bonds of the polysilanes.
\end{abstract}

Keywords: Photocrosslinking, Fluorene, Epoxide, Polysilane, Photoacid generator, High refractive index

\section{Introduction}

Photo-induced control of the network structures of polymers has attracted much attention due to its versatility of special and temporal control in order to fabricate functional materials $[1,2]$. Based on this point of view, recent research regarding the design of polymer networks by dual irradiations has been reviewed [2]. Especially, a photo-degradable system after photopolymerization, photopolymerizable system after photolysis, and photo-cross-linkable system after photopolymerization were introduced. In terms of the photo-degradable system after photopolymerization, a chain length analysis of the networks can be applied in addition to the fabrication of the replicated resin molds [3]. In terms of photo-cross-linkable system after photopolymerization, a novel methacrylate containing a chalcone unit was synthesized and the photopolymerization was controlled by the choice of the photoinitiators and irradiation wavelength [4]. In terms of photopolymerizable system after photolysis, a photocrosslinkable system sensitive to 405-nm light was successfully devised using a novel photoacid generator $[5,6]$. This system is applicable to novel photosensitive materials.

We have become interested in the photocrosslinking of diphenylfluorene and polysilane blends [7-11] as potential functional coatings with a high thermal stability, high transparency, and high refractive indices. Thus, we have developed the photo-induced acid-catalyzed cross-linking system of diepoxyfluorene/polysilane blends in the presence of PAGs by irradiation [7-9]. In the system, the photo-induced acid catalyzed the crosslinking of the epoxides and the terminal groups of the polysilanes. In this study, we extended the previous studies [7-9] to fabricate films with high and tunable refractive indices. We have formed photocrosslinked films of diphenyl- or 
dinaphthylfluorene having epoxy or oxetane moieties and polysilanes blends in the presence of a photoacid generator by irradiation at $405 \mathrm{~nm}$. The refractive indices were controlled by irradiation at $254 \mathrm{~nm}$ using the degradation properties of the polysilanes [12-17]. The photocrosslinking and photodegradation properties were discussed in terms of the structures of the chemicals and irradiation conditions.

\section{Experimental}

7-(1,1-Dimethylethyl)-1,3-dihydro-1,3dioxo- $2 H[1,4]$ benzodithiino[2,3-f] isoindol-2-yl trifluoromethanesulfonate (PAG) [5] was kindly donated by Sanbo Chemical Ind., Ltd. Polymethylphenylsilane (PMPS) $\left(M_{\mathrm{n}}=11000\right)$, hyperbranched polyphenylsilyne [(PSy1, $M_{\mathrm{n}}=$ 1100) and (PSy2, $\left.\left.M_{\mathrm{n}}=1300\right)\right]$, 9,9-bis[(3,4diglycidyloxy)phenyl]fluorene (BCAFG), 9,9bis[(6-glycidyloxy)-2-naphthyl]fluorene (BNFG), and $3,3^{\prime}-[(1-$-fluorenylmethylene $) \quad \operatorname{bis}(6,2-$ naphthylideneoxymethylene)] bis[3methyloxetane] (BNFO) were obtained from Osaka Gas Chemicals Co., Ltd. The structures of these chemicals used are shown in Fig. 1.

Sample films (ca. $1 \mu \mathrm{m}$ ) were prepared by spin-casting from polymer solutions containing fluorene derivatives, polysilanes, and PAG onto a $\mathrm{CaF}_{2}$ plate or silicon wafer. Cyclohexanone and diglyme were used as the solvents.
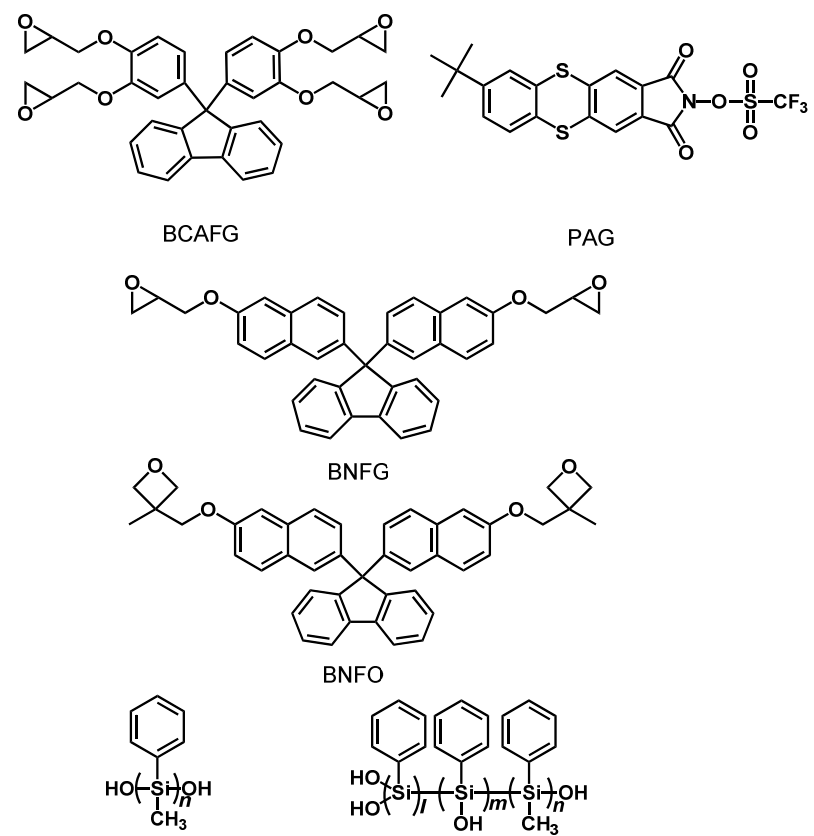

$$
\text { BNFO }
$$

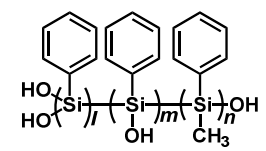

$\operatorname{PMPS}\left(M_{\mathrm{n}}=11000\right) \quad \operatorname{PSy} 1\left(I=3, m=0, n=6, M_{\mathrm{n}}=1100\right)$

Fig. 1. Structures of chemicals used in this study.
Irradiation was performed at $405 \mathrm{~nm}$ using an LED laser (Ball Semiconductor, BP300, $300 \mathrm{~mW}$, $48 \mathrm{~mW} / \mathrm{cm}^{2}$ ) and at $254 \mathrm{~nm}$ using a low pressure mercury lamp (Sen SUV40UL-32, 40 W, 2 $\mathrm{mW} / \mathrm{cm}^{2}$ ) without a filter. The intensity of the light was measured by an Orc Light Measure UV-M02 and Ushio USR-45VA.

Baking of the films was carried out using a conventional hot plate. The irradiated films were soaked in tetrahydrofuran and the insoluble fraction was determined by comparing the film thickness before and after soaking in tetrahydrofuran for $10 \mathrm{~min}$. The thickness of the films was measured by interferometry (Nanometrics Nanospec M3000).

The UV-vis spectra were taken by a Shimadzu UV-2450. The FT-IR measurements were carried out using a JASCO FT/IR-4600. The refractive indices of the films were measured using an Abbe refractometer (ATAGO DR-04).

\section{Results and discussion}

3.1. Photocrosslinking

In a previous study [7], we successfully fabricated the photocrosslinked PMPS/BCAFG $(13 / 87, w t / w t)$ blended film without damaging the Si-Si bonds of PMPS in the film. The PMPS content strongly affects the refractive indices of the films, but also the photocrosslinking reactions. Clear films were obtained with up to a $50 \mathrm{wt} \%$ PMPS content. When the PMPS/BCAFG $(33 / 67, \mathrm{wt} / \mathrm{wt})$ blended film containing $5 \mathrm{wt} \%$ PAG was irradiated at $405 \mathrm{~nm}$ with a dose of $1600 \mathrm{~mJ} / \mathrm{cm}^{2}$ and baked at $110{ }^{\circ} \mathrm{C}$ for $6 \mathrm{~min}$, insolubilization was observed. The effect of the post-exposure-bake (PEB) temperature on the insoluble fractions of the polysilanes/BCAFG blended films irradiated with a dose of 1600 $\mathrm{mJ} / \mathrm{cm}^{2}$ was observed. The insoluble fractions increased with the PEB temperature. Insolubilization was not observed for unirradiated samples after heating below $110{ }^{\circ} \mathrm{C}$. When the polysilanes/BCAFG samples were baked above $120^{\circ} \mathrm{C}$ without irradiation, insolubilizations were observed. The generation of the acid by the decomposition of PAG promotes the crosslinking reactions of BCAFG. Table 1 summarizes the optimum conditions for the preparation of the photocrosslinked polysilanes/diarylfluorene blended films together with their refractive indices. Incorporation of naphthyl units into the blended films can effectively increase the refractive indices. However, the reactivity of 
Table 1. Optimum photocrosslinking conditions of polysilane/diarylfluorene blended films and their refractive indices.

\begin{tabular}{|c|c|c|c|c|c|c|c|c|c|c|c|c|c|c|}
\hline \multicolumn{7}{|c|}{ Formulation (weight ratio) } & \multirow{2}{*}{$\begin{array}{c}\text { Irradiation } \\
\text { dose at } \\
405 \mathrm{~nm} \\
\left(\mathrm{~mJ} / \mathrm{cm}^{2}\right)\end{array}$} & \multirow{2}{*}{$\begin{array}{l}\text { Heating } \\
\text { temp. }\left({ }^{\circ} \mathrm{C}\right)\end{array}$} & \multirow{2}{*}{$\begin{array}{l}\text { Heating } \\
\text { time (min) }\end{array}$} & \multirow{2}{*}{$\begin{array}{l}\text { Insoluble } \\
\text { fraction } \\
(\%)\end{array}$} & \multirow{2}{*}{$n_{\mathrm{F}}^{\mathrm{a}}$} & \multirow{2}{*}{$n_{\mathrm{D}}^{\mathrm{b}}$} & \multirow{2}{*}{$n_{\mathrm{C}}^{\mathrm{c}}$} & \multirow{2}{*}{$v_{d}^{d}$} \\
\hline PMPS & PSy1 & PSy2 & BCAFG & BNFG & BNFO & PAG & & & & & & & & \\
\hline \multirow[t]{3}{*}{33} & & & 67 & & & 5 & 1600 & 110 & 6 & 92 & 1.645 & 1.619 & 1.617 & 22 \\
\hline & 33 & & 67 & & & 5 & 1600 & 110 & 6 & 78 & 1.641 & 1.622 & 1.618 & 27 \\
\hline & & 33 & 67 & & & 5 & 1600 & 110 & 6 & 76 & 1.640 & 1.621 & 1.616 & 26 \\
\hline 33 & & & & 67 & & 5 & 1600 & 110 & 6 & 0 & $-e$ & $-{ }^{e}$ & $-\mathrm{e}$ & $-\mathrm{e}$ \\
\hline 33 & & & & & 67 & 5 & 1600 & 110 & 6 & 0 & $\mathrm{e}^{\mathrm{e}}$ & $-\mathrm{e}$ & $-\mathrm{e}$ & $\mathrm{e}^{\mathrm{e}}$ \\
\hline 33 & & & & 6.7 & 60 & 5 & 1600 & 150 & 5 & 78 & 1.723 & 1.688 & 1.689 & 17 \\
\hline
\end{tabular}

${ }^{a}$ Measured at $486 \mathrm{~nm} .{ }^{b}$ Measured at $589 \mathrm{~nm} .{ }^{~}$ Measured at $656 \mathrm{~nm} .{ }^{\mathrm{d}}$ Abbe number : $\left(n_{\mathrm{D}}-1\right) /\left(n_{\mathrm{F}}-n_{\mathrm{C}}\right) .{ }^{\mathrm{e}}$ Not measured.

BNFG, a difunctional epoxide, and BNFO, a difunctional oxetane derivative, were lower than that of BCAFG, a tetrafunctional epoxide, due to the low functionality of BNFG and BNFO (Table 1 , columns 4 and 5). When the PMPS/BNFG $(33 / 67$, wt $/ \mathrm{wt})$ and the PMPS/BNFO (33/67, $\mathrm{wt} / \mathrm{wt}$ ) blended film containing $5 \mathrm{wt} \%$ of $\mathrm{PAG}$ were baked at $150{ }^{\circ} \mathrm{C}$, insolubilization was observed for both films. We consider that we overcome the low photo-contrast by mixing epoxy to oxetane moiety. The addition of oxetane to the epoxide is known to increase the reactivity of cationic photopolymerizations [18-20]. When the PMPS/BNFG/BNFO $(33 / 6.7 / 60, \mathrm{wt} / \mathrm{wt} / \mathrm{wt})$ blended film containing 5 $\mathrm{wt} \%$ of PAG was irradiated at $405 \mathrm{~nm}$ with a dose of $1600 \mathrm{~mJ} / \mathrm{cm}^{2}$ and baked at $150{ }^{\circ} \mathrm{C}$ for $5 \mathrm{~min}$, insolubilization was observed. No insolubilization was observed without irradiation. The photocrosslinked film showed a high refractive index $\left(n_{\mathrm{d}}: 1.70\right)$.

\subsection{Photodegradation}

Figure 2 shows the effect of the irradiation dose on the UV spectral changes of the PMPS/BCAFG blended films irradiated at 254 $\mathrm{nm}$. The shoulder at around $330 \mathrm{~nm}$ ascribed to the $\mathrm{Si}-\mathrm{Si}$ bonds decreased with the irradiation dose. More than $70 \%$ of the shoulder disappeared after irradiation with a dose of 16000 $\mathrm{mJ} / \mathrm{cm}^{2}$. When using PSy1 and PSy2 instead of PMPS, a decrease in the shoulder during irradiation was also observed. FT-IR measurements also revealed the decomposition of the $\mathrm{Si}-\mathrm{Si}$ bonds in the blends as discussed below.

Figure 3 shows the effect of the irradiation dose on the refractive index changes of the

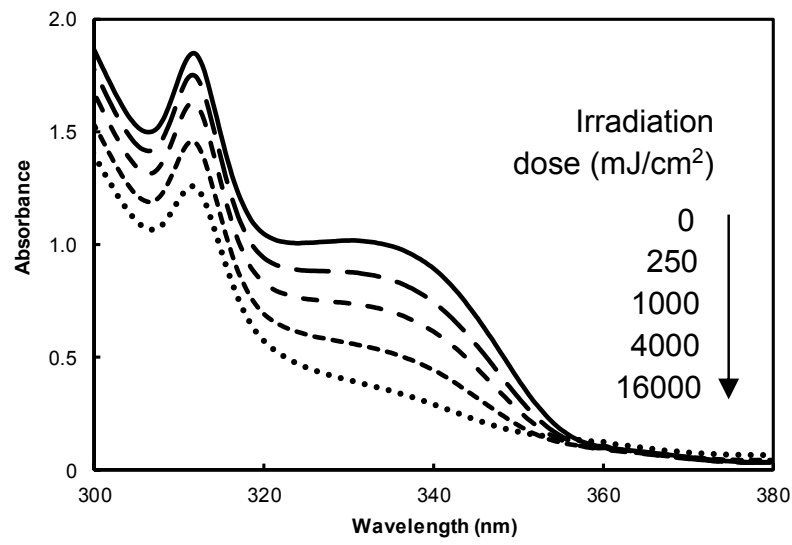

Fig. 2. Effect of irradiation at $254 \mathrm{~nm}$ on UV spectral changes of PMPS/BCAFG (33/67, wt/wt) blended films containing $5 \mathrm{wt} \%$ PAG. 405-nm irradiation dose: $1600 \mathrm{~mJ} / \mathrm{cm}^{2}$. PEB condition: $110^{\circ} \mathrm{C}$ for $6 \mathrm{~min}$. Film thickness: 1.1-1.3 $\mu \mathrm{m}$.

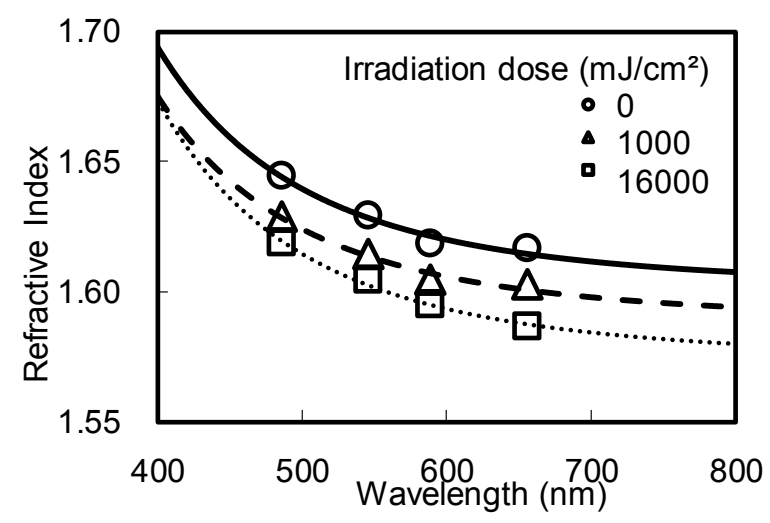

Fig. 3. Effect of irradiation dose at $254 \mathrm{~nm}$ on refractive index changes of PMPS/BCAFG (33/67, wt/ wt) blended films containing $5 \mathrm{wt} \% \mathrm{PAG}$. 
Table 2. Optical properties of photocrosslinked PMPS/BCAFG (33/67, wt/wt) blended films upon irradiation at $254 \mathrm{~nm}$.

\begin{tabular}{|c|c|c|c|c|}
\hline $\begin{array}{l}\text { Irradiation dose } \\
\text { at } 254 \mathrm{~nm} \\
\qquad\left(\mathrm{~mJ} / \mathrm{cm}^{2}\right)\end{array}$ & $n_{\mathrm{F}}{ }^{\mathrm{a}}$ & $n_{\mathrm{D}}^{\mathrm{b}}$ & $n_{C}{ }^{c}$ & $v_{\mathrm{d}}{ }^{\mathrm{d}}$ \\
\hline 0 & 1.645 & 1.629 & 1.619 & 22 \\
\hline 1000 & 1.629 & 1.614 & 1.605 & 23 \\
\hline 16000 & 1.610 & 1.595 & 1.584 & 19 \\
\hline
\end{tabular}

Table 3. Optical properties of photocrosslinked PMPS/BNFG/BNFO (33/6.7/60, wt/wt/wt) blended films upon irradiation at $254 \mathrm{~nm}$.

\begin{tabular}{rllll}
\hline $\begin{array}{c}\text { Irradiation dose } \\
\text { at } 254 \mathrm{~nm} \\
\left(\mathrm{~mJ} / \mathrm{cm}^{2}\right)\end{array}$ & $n_{\mathrm{F}}{ }^{\mathrm{a}}$ & $n_{\mathrm{D}}{ }^{\mathrm{b}}$ & $n_{\mathrm{C}}{ }^{\mathrm{c}}$ & $v_{\mathrm{d}}{ }^{\mathrm{d}}$ \\
\hline 0 & 1.723 & 1.698 & 1.689 & 17 \\
1000 & 1.718 & 1.691 & 1.682 & 19 \\
4000 & 1.707 & 1.685 & 1.676 & 21 \\
16000 & 1.695 & 1.672 & 1.662 & 20 \\
64000 & 1.683 & 1.657 & 1.651 & 21 \\
\hline
\end{tabular}

${ }^{\text {a}}$ Measured at $486 \mathrm{~nm}$. ${ }^{\mathrm{b}}$ Measured at $589 \mathrm{~nm}$.

${ }^{\mathrm{c}}$ Measured at $656 \mathrm{~nm}$. ${ }^{\mathrm{d}}$ Abbe number : $\left(n_{\mathrm{D}}-1\right) /\left(n_{\mathrm{F}}-n_{\mathrm{C}}\right)$.

PMPS/BCAFG blended films irradiated at 254 nm. The crosslinked PMPS/BCAFG blended film showed a high refractive index $\left(n_{\mathrm{d}}=1.62\right)$. The refractive index value decreased to 1.58 after irradiation at $254 \mathrm{~nm}$ with a dose of 16000 $\mathrm{mJ} / \mathrm{cm}^{2}$. Using PSy1 and PSy2 instead of PMPS, a decrease in the refractive indices during irradiation was also observed. The structures of the polysilanes did not strongly affect the decreased values.

Tables 2 and 3 summarize the effect of the irradiation dose on the refractive index changes of the PMPS/diarylfluorene blended films irradiated at $254 \mathrm{~nm}$.

The crosslinked PMPS/BNFG/BNFO (33/6.7/60, wt/wt/wt) blended films (Table 3) showed a high refractive index $\left(n_{\mathrm{d}}=1.70\right)$. The refractive index value decreased to 1.66 after irradiation at $254 \mathrm{~nm}$ with a dose of 64000 $\mathrm{mJ} / \mathrm{cm}^{2}$.

\subsection{Reaction mechanism}

The UV-vis spectral changes of the PMPS/BCAFG blended films revealed that less than $10 \%$ of the intensities of the shoulders at around $330 \mathrm{~nm}$ ascribed to the $\mathrm{Si}-\mathrm{Si}$ bonds of PMPS decreased upon irradiation and baking at $110{ }^{\circ} \mathrm{C}$ for $6 \mathrm{~min}$. The UV-vis spectral changes of the PSy1/BCAFG and PS2/BCAFG blended films were slightly observed like the PMPS/BCAFG ones.

As already mentioned, effective scissions of the Si-Si bonds in the blended films were clearly observed upon irradiation at $254 \mathrm{~nm}$ as shown in Fig. 2.

The FT-IR spectral changes revealed the reaction mechanism of the blended films. Figure 4 shows the FT-IR spectral changes of the photocrosslinked PMPS/BCAFG blended films upon irradiation at $254 \mathrm{~nm}$. The broad peak at around $3400 \mathrm{~cm}^{-1}$ ascribed to the Si-O-H stretching and at $1100 \mathrm{~cm}^{-1}$ ascribed to the Si-O-Si stretching increased with the irradiation dose. On the other hand, the peak at around $1500 \mathrm{~cm}^{-1}$ ascribed to the phenyl ring slightly decreased.

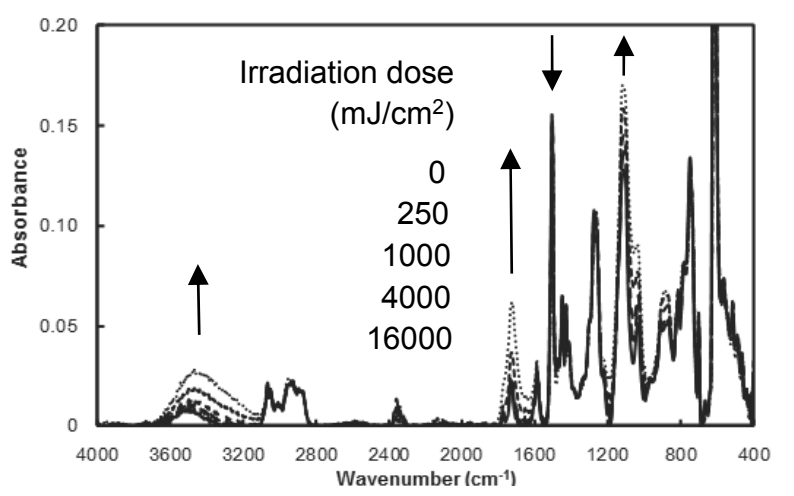

Fig. 4. Effect of irradiation at $254 \mathrm{~nm}$ on FT-IR spectral changes of PMPS/BCAFG (33/67, wt/wt) blended films containing $5 \mathrm{wt} \%$ PAG. 405-nm irradiation dose: $1600 \mathrm{~mJ} / \mathrm{cm}^{2}$. PEB condition: $110^{\circ} \mathrm{C}$ for $6 \mathrm{~min}$. Film thickness: 1.1-1.3 $\mu \mathrm{m}$.

Scheme 1 shows a plausible reaction mechanism of the PMPS/BNFG/BNFO blended system. Upon irradiation at $405 \mathrm{~nm}$, PAG photolyzed to produce an acid. The generated acid promotes the crosslinking reactions which were mainly due to the acid-catalyzed polymerization of the epoxy and oxetane moieties. It is known that initiation of the epoxy is faster than that of oxetane in the cationic polymerization [18-20]. The polymerization induced the insolubilization of the films due to the nature of the difunctional compounds of 

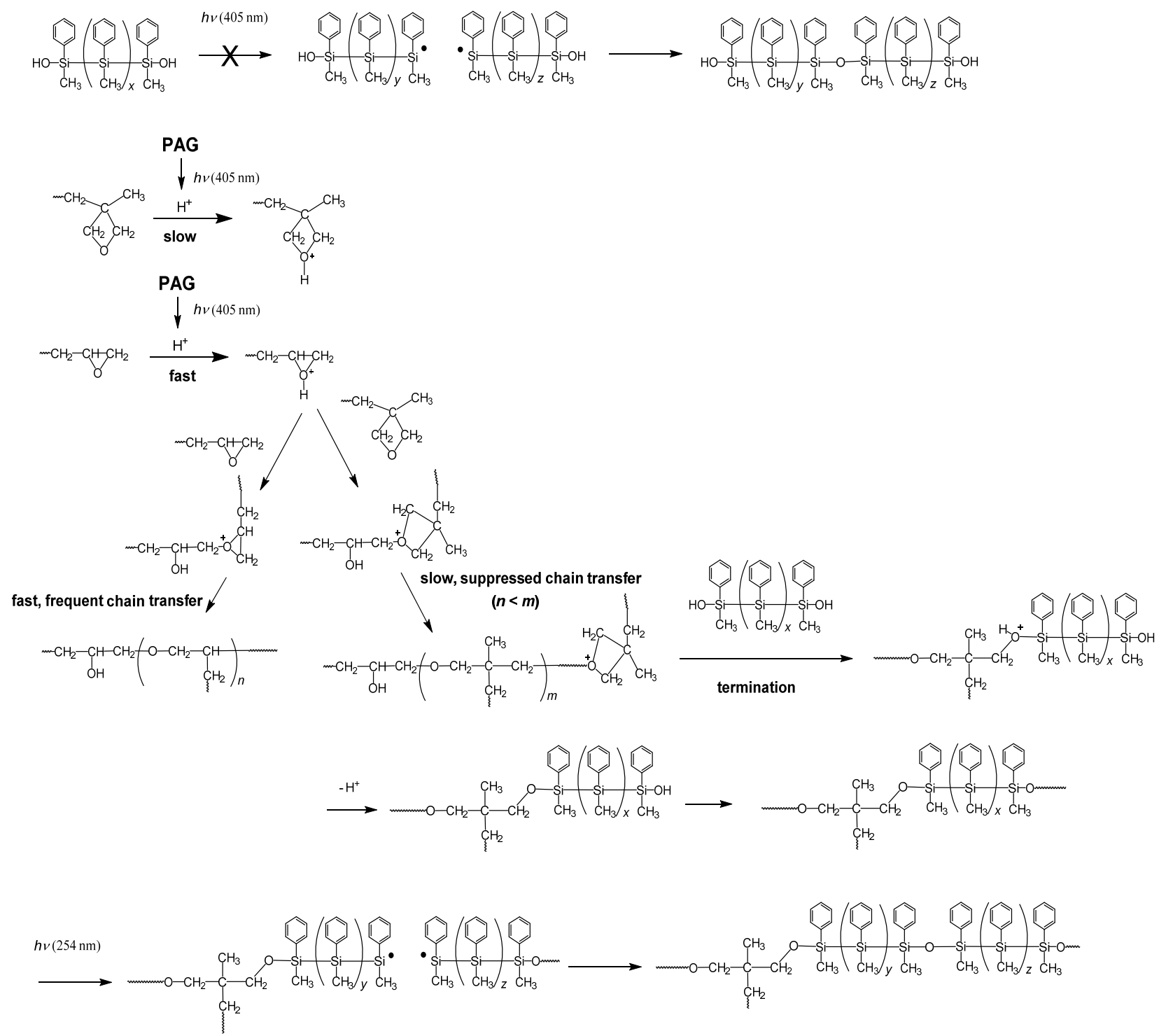

Scheme 1. Plausible reaction mechanism of PMPS/BNFG/BNFO blended system.

BNFG and BNFO. The chain length of the oxetane polymer is higher than that of epoxy polymer, i.e., $m>n$ in Scheme 1 [18-20]. Mixing BNFG and BNFO in the blended films effectively enhanced the photocrosslinking reactions. The termination of the polymerization by the terminal $\mathrm{OH}$ groups of the polysilanes also occurred as a minor reaction. We consider that the $\mathrm{Si}-\mathrm{Si}$ bonds in the polysilanes were not photolyzed by the visible light.

Upon irradiation at $254 \mathrm{~nm}$, the Si-Si bonds in PMPS easily photolyzed to generate Si radicals [12-14]. After sequential reactions of the $\mathrm{Si}$ radicals with $\mathrm{O}_{2}$ in the atmosphere, scission of the
O-O bonds, hydrogen abstraction, and condensation of the generated $\mathrm{Si}-\mathrm{OH}$ groups, the Si-O-Si bonds are introduced in the blended films which reduced the refractive indices (see Fig. 3, Tables 2 and 3).

\section{Conclusion}

We succeeded in the preparation of photocrosslinked polysilanes/diarylfluorenes blended films and controlled their refractive indices upon irradiation at $254 \mathrm{~nm}$. We have successfully fabricated films with high refractive indices $\left(n_{\mathrm{d}}: 1.70\right)$. Photodecomposition of the Si-Si bonds of polysilanes effectively occurred on irradiation at $254 \mathrm{~nm}$. A decrease of about 0.04 
of refractive indices was observed after the photodecomposition at $254 \mathrm{~nm}$. The changes in the refractive indices were not strongly affected by the structures of the polysilanes.

\section{Acknowledgement}

This study was partly supported by JSPS KAKENHI Grant Numbers JP24550260 and JP16H02986.

\section{References}

1. J. P. Fouassier and J. F. Rabek, "Radiation Curing in Polymer Science and Technology", Elsevier Applied Science, New York (1993).

2. H. Okamura, J. Network Polym. Jpn., 27 (2016) 224 (in Japanese).

3. D. Matsukawa, H. Okamura, and M. Shirai, $J$. Photopolym. Sci. Technol., 23 (2010) 125.

4. H. Okamura, Y. Ueda, and M. Shirai, $J$. Photopolym. Sci. Technol., 26 (2013) 245.

5. H. Okamura, H. Naito, and M. Shirai, J. Photopolym. Sci. Technol., 21 (2008) 285.

6. H. Okamura and M. Shirai, Trends Photochem. Photobiol., 15 (2013) 51.

7. H. Okamura, K. Funamoto, A. Matsumoto, K. Minokami, and S. Miyauchi, J. Photopolym. Sci. Technol., 27 (2014) 525.

8. H. Okamura, K. Sakai, M. Tsunooka, M. Shirai, T. Fujiki, S. Kawasaki, and M. Yamada, J. Photopolym. Sci. Technol., 16 (2003) 87.

9. H. Okamura, C. Harada, M. Tsunooka, T.
Fujiki, S. Kawasaki, M. Yamada, and M. Shirai, Kobunshi Ronbunshu, 61 (2004) 75 (in Japanese).

10. A. Rahim, N. Azura, and M. Fujiki, Polym. Chem., 7 (2016) 4618.

11. V. Cimrova and D. Vyprachticky, Appl. Phys. Lett., 82 (2003) 642.

12. T. Sato, N. Nagayama, and M. Yokoyama, $J$. Photopolym. Sci. Technol., 16 (2003) 679.

13. K. Matsukawa, K. Katada, N. Nishioka, Y. Matsuura, and H. Inoue, J. Photopolym. Sci. Technol., 17 (2004) 51.

14. K. Matsukawa, Y. Matsuura, Y. Michiwaki, M. Chikaraishi, and H. Naito, J. Photopolym. Sci. Technol., 22 (2009) 307.

15. T. Kitao, S. Bracco, A. Comotti, P. Sozzani, M. Naito, S. Seki, T. Uemura, and S. Kitagawa, J. Am. Chem. Soc., 137 (2015) 5231.

16. F. Schauer, P. Schauer, I. Kuritka, and H. Bao, Mater. Trans., 51 (2010) 197.

17. A. Sharma, M. Katiyar, Deepak, S. K. Sanjeev, and S. Seki, J. Appl. Phys., 102 (2007) 104902.

18. H. Sasaki, J. M. Rudzinski, and T. Kakuchi, $J$. Polym. Sci., Part A: Polym. Chem., 33 (1995) 1807.

19. J. V. Crivello, Polymer, 64 (2015) 227.

20. J. V. Crivello, J. Polym. Sci., Part A: Polym. Chem., 52 (2014) 2934. 